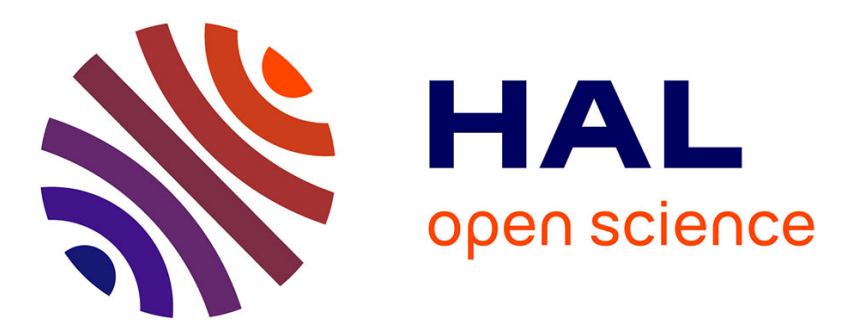

\title{
Design optimization and optimal control for hybrid vehicles
}

Yohan Milhau, Delphine Sinoquet, Grégory Rousseau

\section{To cite this version:}

Yohan Milhau, Delphine Sinoquet, Grégory Rousseau. Design optimization and optimal control for hybrid vehicles. Optimization and Engineering, 2011, 12 (1-2), pp.199-213. 10.1007/s11081-009-91008. hal-02284149

\section{HAL Id: hal-02284149 \\ https://hal-ifp.archives-ouvertes.fr/hal-02284149}

Submitted on 11 Sep 2019

HAL is a multi-disciplinary open access archive for the deposit and dissemination of scientific research documents, whether they are published or not. The documents may come from teaching and research institutions in France or abroad, or from public or private research centers.
L'archive ouverte pluridisciplinaire HAL, est destinée au dépôt et à la diffusion de documents scientifiques de niveau recherche, publiés ou non, émanant des établissements d'enseignement et de recherche français ou étrangers, des laboratoires publics ou privés. 


\title{
Design optimization and optimal control for hybrid vehicles
}

\author{
Delphine Sinoquet • Gregory Rousseau • \\ Yohan Milhau
}

Received: 30 October 2008 / Accepted: 16 November 2009 / Published online: 17 December 2009

(C) Springer Science+Business Media, LLC 2009

\begin{abstract}
In the context of growing environmental concerns, hybrid-electric vehicles appear to be one of the most promising technologies for reducing fuel consumption and pollutant emissions.

This paper presents a parametric study focused on variations of the size of the powertrain components, and optimization of the power split between the engine and electric motor with respect to fuel consumption. To take into account the ability of the engine to be turned off, and the energy consumed to start the engine, we consider a second state to represent the engine: this state permits to obtain a more realistic engine model than it is usually done. Results are obtained for a prescribed vehicle cycle thanks to a dynamic programming algorithm based on a reduced model, and furnish the optimal power repartition at each time step regarding fuel consumption under constraints on the battery state of charge, and may then be used to determine the best components of a given powertrain.

To control the energy sources in real driving conditions, when the future is unknown, a real-time control strategy is used: the Equivalent Consumption Minimization Strategy (ECMS). In this strategy, the battery is being considered as an auxiliary reversible fuel reservoir, using a scaling parameter which can be deduced from dynamic programming results. Offline optimization results and ECMS are compared for a realistic hybrid vehicle application.
\end{abstract}

Keywords Hybrid vehicles · Optimal control · Dynamic programming · Pontryagin's principle

D. Sinoquet $(\bowtie) \cdot G$. Rousseau $\cdot$ Y. Milhau IFP, 1 et 4 avenue de Bois-Préau, 92852 Rueil-Malmaison Cedex, France e-mail: delphine.sinoquet@ifp.fr 


\section{Introduction}

Growing environmental concerns coupled with concerns about global crude oil supplies stimulate research on new vehicle technologies. Hybrid-electric vehicles (HEV) appear to be one of the most promising technologies for reducing fuel consumption and pollutant emissions (German 2003). Indeed, it is well known that the kinetic energy gained by the classical vehicle after an acceleration can not be recuperated when braking. One of the advantage of the hybrid vehicle is its ability to recuperate a part (depending of efficiencies) of this energy, to store it in a battery, and to re-use it latter. This electric energy can therefore be used by an electric motor to power the vehicle and to save fuel.

Among all the possible configurations for typical HEV, the parallel powertrain is one of the most effective. In a parallel HEV, an electric machine furnishes a traction power alongside with the engine. The benefits of such system come from its ability to provide a traction force to the drive train either with the engine, either with the only electric motor, or with the both. It is thus possible to power the vehicle only with the electric motor, while the engine is being off. Such powertrain configuration has often been studied to minimize fuel consumption (see Sciarretta et al. 2004; Wu et al. 2002; Delprat et al. 2004; Paganelli et al. 2002). Nevertheless, extra fuel consumption at engine starts is never taken into account; we propose in the later to define a new state to deal with this start-up cost.

The control of hybrid powertrains is more complex than control of classic engine. Actually, the control laws have to deal with the state of charge of the battery, which provides the level of remaining electric energy, and with the variable efficiency of each element of the powertrain. To find the global optimal solution, control techniques such as linear programming, optimal control (Delprat et al. 2004; Guzzella and Sciarretta 2005), and especially dynamic programming (DP) (Wu et al. 2002; Guilbaud 2002; Liu and Peng 2006; Sundström et al. 2008) have been studied. Optimization of energy management strategies on given driving cycles is often used. In general, these techniques do not offer an on-line solution for real-time control, because they assume that the future driving cycle is completely known. Nevertheless, their results can be used as a benchmark for the performance of other strategies, to perform a parametric study, or to derive sub-optimal control laws to be implemented on a vehicle.

The objective of the parametric study is to determine the influence of component sizes on the fuel consumption, and to find the optimal size of some predominant elements for a prescribed driving cycle. In Bonnans et al. (2002), the author considers a bilevel optimization problem, with a simultaneous optimization of design parameters and trajectories. Although the implementation of this method is complicated, and the computation time is high, it allows obtaining the exact optimal size of several elements along a driving cycle. Some other studies (Sharer et al. 2006; Assanis et al. 1999) consider more accurate models, but do not control engine and electric motor with an optimal controller. In this context, we chose to test different component size values, and to get the best size obtained on an optimal trajectory, thanks to a dynamic programming algorithm.

Among sub-optimal control laws used as real-time controller, ECMS (Paganelli et al. 2002; Sciarretta et al. 2004) is based on physical considerations, and is then 
applicable much more generally than rule-based controllers. This controller is inspired from the Pontryagin Principle, and thus some links can be done between parameters of this controller and dynamic programming results (Bryson and Ho 1975; Pontryagin et al. 1965). The performance of this controller resides in the control of the energy ratio (called $p$ in the following) between electrical energy and fuel energy.

In a first part of this paper, we focus on a Citroën $\mathrm{C} 1$, equipped with a gasoline engine displacement of $1000 \mathrm{cc}$. From this vehicle, we consider an additional source of power given by an electric motor located near the wheels. This motor takes its energy from an additional battery. A model of this powertrain has been implemented in AMESim environment for validation purposes, and also in Matlab, for optimization. The later model is a simplified static model that allows fast computations, and includes the start-up cost of the engine. Two different optimization algorithms are presented and applied on this model, depending on the needs:

- a Dynamic Programming algorithm (Sciarretta et al. 2004; Scordia 2005; Wu et al. 2002), which provides the optimal control strategy on a prescribed cycle, and the potential of a powertrain. In the algorithm is considered the extra fuel consumption (called $L_{2}$ in the following),

- a sub-optimal control law, based on the Principle of Pontryagin, used as a real-time control law.

\section{System modelling and optimal control problem}

\subsection{Optimal control problem}

The optimal control problem under study consists in minimizing the fuel consumption of the vehicle along a prescribed vehicle cycle, taking into account physical constraints from battery, engine and electric motor.

Let $x_{1}$ be a state, corresponding to the state of charge of the battery and $x_{2} \in\{0,1\}$ be a discrete state representing the state of the engine: $x_{2}=0$ means the engine is off, while $x_{2}=1$ means the engine is on. We denote by $x=\left\{x_{1}, x_{2}\right\}$ the state vector.

We define the control $u=\left\{u_{1}, u_{2}, u_{3}\right\} \in U\left(x_{2}, t\right)$ by

$$
u= \begin{cases}u_{1} & \text { the power split ratio between the engine and the electric motor } \\ u_{2} & \text { the gear number, } \\ u_{3} & \text { starting up/stopping the engine, }\end{cases}
$$

with $U\left(x_{2}, t\right)$ is such that

$$
U\left(x_{2}, t\right)=\left\{\left(u_{1}, u_{2}, u_{3}\right) \backslash u_{1} \in U_{1}\left(x_{2}, t\right), u_{2} \in U_{2}(t), u_{3} \in U_{3}\left(x_{2}\right)\right\},
$$

where $U_{1}\left(x_{2}, t\right)=\left[u_{1}^{\min }, u_{1}^{\max }\right], U_{2}(t)$ are discrete values, and $U_{3}\left(x_{2}\right)$ are discrete values $\{-1,0\}$ or $\{0,1\}$ depending on $x_{2}$ value (see Sect. 3). The control $u_{1}$ corresponds to the classical control for HEV, $u_{2}$ may be optimized too, especially for automatic transmissions or CVT transmissions (continuous variation of the gear ratio), and $u_{3}$ is only linked to $x_{2}$ state. 

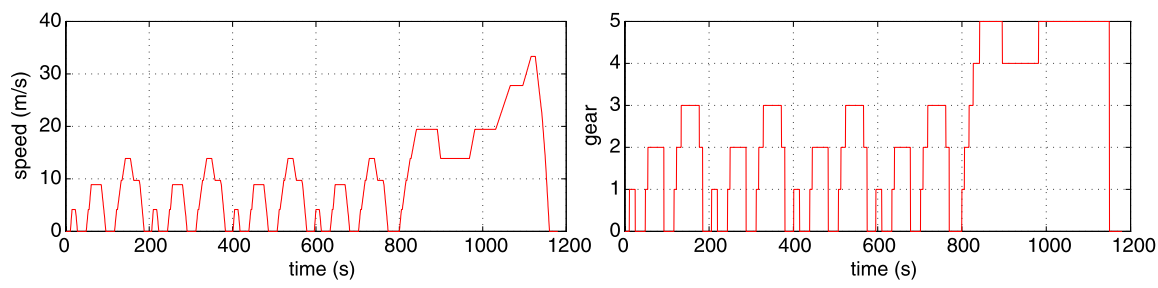

Fig. 1 NEDC driving cycle: vehicle speed at left, gear ratio at right

Let $g\left(x_{1}(T), T\right)$ be a penalization term handling a constraint on the final state of charge of the battery, and $L(x(t), u(t), t)$ be the instantaneous fuel consumption, given by

$$
L(x(t), u(t), t)= \begin{cases}L_{1}\left(u_{1}(t), t\right) & \text { if } x_{2}=1 \text { (engine started) } \\ 0 & \text { if } x_{2}=0 \text { (engine stopped) } \\ L_{2} & \text { if } x_{2}=0 \text { and } u_{3}=1 \text { (engine start-up) }\end{cases}
$$

While $x_{1}(t)$ is a continuous state governed by $\dot{x}_{1}(t)=f_{1}(u(t), t)$, the state $x_{2}(t)$ is a discrete state, and takes only the values 0 or 1 corresponding to engine stopped/engine started. The introduction of $x_{2}(t)$ permits to take into account an extra fuel consumption, $L_{2}$, corresponding to the necessary energy to start the engine. Physically, this energy comes from the inertia of the engine, and is consumed by the starter (electric energy), and by the engine (small quantity of fuel to reach the idle speed). The value $L_{2}$ is considered as a constant.

The general optimization problem is the following:

$$
\left\{\begin{array}{l}
\min _{u \in U}\left\{J(u):=\int_{0}^{T} L(x(t), u(t), t) d t+g\left(x_{1}(T), T\right)\right\} \\
\text { subject to: } \\
\dot{x}_{1}(t)=f_{1}\left(u_{1}(t), t\right), \quad x_{1}(0)=x_{1,0}, \\
x_{2}\left(t^{+}\right)=x_{2}(t)+u_{3}(t), \quad x_{2}(0)=x_{2,0} \\
x_{1}^{\min } \leq x_{1}(t) \leq x_{1}^{\max }
\end{array}\right.
$$

where 0 and $T$ are respectively the initial and the final times of the prescribed driving cycle, and $f_{1}$ represents the dynamics of the battery.

This minimization problem must be solved on a prescribed cycle, for instance the NEDC cycle, Fig. 1. Thanks to a vehicle model (mass, wheel diameter, aerodynamic coefficients, etc.) and the vehicle speed request $V_{v}(t)$, the requested torque $T_{w}(t)$ and speed $\omega_{w}(t)$ at the wheels are computed. In this optimization problem, we consider the cycle as a wheel torque $T_{w}(t)$ and wheel speed $\omega_{w}(t)$ trajectory to be followed.

\subsection{System modelling}

In this application, we consider that the engine is located upstream of the gearbox, as on conventional vehicles. Besides, the electric motor is located downstream of the gearbox, beside the wheels. Let us introduce now some useful notations to describe the powertrain and to define the control $u(t)$ : 
- the requested torque at wheels is written as $T_{w}(t)=R_{f a r} R_{g r} T_{e}(t)+T_{m}(t)+$ $T_{b k}(t)$, and can be achieved thanks to the engine torque $T_{e}(t)$ multiplied by the front axle ratio $R_{f a r}$ and by the gear ratio $R_{g r}$, and thanks to the motor torque $T_{m}(t)$. A brake torque $T_{b k}(t)$ can also be applied by braking system.

- the engine torque is $T_{e}(t)=u_{1}(t) T_{w}(t) /\left(R_{f a r} R_{g r}\right)$,

- the electric motor torque is $T_{m}(t)=\left(1-u_{1}(t)\right) T_{w}(t)$.

During braking phases, $T_{r q}(t)<0$, the braking torque can complete the electric motor torque to slow down the vehicle: $T_{b k}(t)=T_{w}(t)-T_{m}^{\min }(t)$ with $T_{m}^{\min }(t)$ the minimal electric motor torque depending on the engine speed, thus depending on time.

A simple model of the battery is implemented, the state of charge of the battery evolving as

$$
\dot{x}_{1}(t)=f\left(u_{1}(t), t\right)=-\frac{\omega_{m}(t) T_{m}(t) K^{\prime}}{U_{\text {batt }}(t) n_{\text {capa }}}
$$

with $\omega_{m}(t)$ the electric motor speed, $U_{\text {batt }}(t)$ the battery voltage, $K^{\prime}$ an efficiency, and $n_{\text {capa }}$ the nominal capacity of the battery. In the following, we assume that the battery voltage is constant along the cycle. We set $K=\frac{K^{\prime}}{U_{\text {batt }} \cdot n_{\text {capa }}}$ and by replacing $T_{m}(t)$ by its expression, we obtain

$$
\dot{x}_{1}(t)=-K \omega_{m}(t)\left(1-u_{1}(t)\right) T_{w}(t) .
$$

This very simple model for battery dynamics may be complexified to take into account resistive loses.

The state equation for $x_{2}$ is $\dot{x}_{2}=0$. It is easier to consider $x_{2}$ in discrete time to understand its behavior (see Sect. 3).

In this optimal control problem, we make several assumptions about the powertrain: (i) the wheel speed $\omega_{w}$ is equal to the electric motor speed $\omega_{m}$, (ii) as the optimization problem is applied on a full hybrid vehicle, the engine can be stopped when the torque is provided only by the electric motor. As mentioned above in the definition of $L(x(t), u(t), t)$, a fuel consumption penalty corresponding to the necessary energy to start the engine must be considered, (iii) recharging the battery is possible for negative torques (braking request) or by an additional engine torque beyond the driver request torque. In the last case, the command $u_{1}(t)$ is larger than 1 , (iv) we consider that the average efficiency of the electric motor is 0.85 .

As in the general optimal control problem (4), the command variables $u(t)$ and the state variables $x(t)$ are submitted to several constraints:

- the engine can only produce a positive torque, and is limited to a maximal torque which depends on engine speed $\omega(t): 0 \leq T_{e}(t) \leq T_{e}^{\max }(\omega(t))$,

- the electric motor torque is bounded: $T_{m}^{\min }(\omega(t)) \leq T_{m}(t) \leq T_{m}^{\max }(\omega(t))$,

- the storage capacity implies a minimal and a maximal state of charge of the battery (which are fixed to $50 \%$ and $70 \%$ in our study): $x_{(1) \min } \leq x_{1}(t) \leq x_{(1) \max }$,

- the final state of charge is constrained to be close to the initial state of charge to maintain a null electrical energy balance (to avoid to discharge totally the battery for minimizing the consumption) $x_{1}(0)=x_{1}(T)$. 
Notice that $T_{w}(t)$ and $\omega_{w}(t)$, which depend on the vehicle model, are computed thanks to a quasistatic approach (Beck et al. 2007; Tate and Boyd 2007; Anatone et al. 2005):

$$
\begin{aligned}
\omega_{w}(t)= & \frac{V_{v}(t)}{r_{w h}} \\
T_{w}(t)= & -\frac{1}{r_{w h}}\left(m g \sin \alpha+\operatorname{Fr}\left(V_{v}(t)\right)+\frac{1}{2} \rho S C_{x}\left(V_{v}(t)+v_{0}\right)^{2}\right. \\
& \left.-\left(m+\frac{J_{w h}}{r_{w h}^{2}}\right) \frac{d V_{v}(t)}{d t}\right),
\end{aligned}
$$

where $r_{w h}$ is the wheel radius, $\alpha$ is the road slope, $\frac{1}{2} \rho S C_{x}\left(V_{v}(t)+v_{0}\right)^{2}$ corresponds to the aerodynamic loses, $\operatorname{Fr}\left(V_{v}(t)\right)$ is the rolling resistance force, $m$ is the vehicle mass, $J_{w h}$ is the wheel inertia, and $v_{0}$ corresponds to the wind speed (null here).

Constraints on command $u_{1}(t)$ are directly derived from the constraints on maximal and minimal engine and electric motor torque

$$
\begin{aligned}
u_{1}(t) T_{r q}(t) & \leq T_{e}^{\max }(t), \\
T_{m}^{\min }(t) & \leq\left(1-u_{1}(t)\right) T_{r q}(t) \leq T_{m}^{\max }(t) .
\end{aligned}
$$

\section{Dynamic programming}

The Dynamic Programming method (DP) is classically applied to solve the problem (4) (Scordia 2005; Wu et al. 2002): it relies on a very simple idea, the principle of optimality, stated by Richard Bellman. It states that an optimal policy can be built step by step, first by building an optimal control for the "tail subproblem" involving the last step, then by extending the optimal policy to the "tail subproblem" involving the last two stages, and by iterating until an optimal control has been built for the complete time interval. Thus, the optimization problem is solved backward from final time to initial time.

The criterion to be minimized in (4) is thus discretized in time, leading to

$$
\min _{u \in U} J(u):=\sum_{k=0}^{N-1} L\left(x_{k}, u_{k}, k\right) \Delta t+g\left(x_{1, N}\right),
$$

where $L\left(x_{k}, u_{k}, k\right) \Delta t$ is the cumulated fuel consumption over the time interval $[k, k+1], x_{k}$ is the state vector at step time $k$, and $N$ is the final time of the driving cycle. The constraint on the final state of charge $x_{1,0}=x_{1, N}$ has been introduced via a penalization term $g\left(x_{1, N}\right)=\beta\left(x_{1, N}-x_{1,0}\right)^{2}$, with $\beta$, a constant to be chosen.

In general, $\beta$ is most probably different for battery size. However, the same value of $\beta$, chosen high enough, has been used for all the tested battery capacities. 
Notice that this minimization must be done under state constraints $x_{1} \leq x^{\max }$ and $x_{2} \geq x^{\mathrm{min}}$, and the control $\left(u_{1}, u_{2}, u_{3}\right)=u \in U=\left\{U_{1}, U_{2}, U_{3}\right\}$ with

$$
\left\{\begin{array}{l}
U_{1}\left(x_{2}, k\right)=\left[u_{1}^{\min }\left(x_{2}, k\right), u_{1}^{\max }\left(x_{2}, k\right)\right], \\
U_{2}(k)=\llbracket \mathrm{g}^{\min }(k), \ldots, \mathrm{g}^{\max }(k) \rrbracket, \\
U_{3}\left(x_{2}\right)= \begin{cases}\{-1,0\} & \text { if } x_{2}=1, \\
\{0,1\} & \text { if } x_{2}=0,\end{cases}
\end{array}\right.
$$

where $\mathrm{g}^{\min }(k)$ and $\mathrm{g}^{\max }(k)$ correspond to minimal and maximal allowed gears (which are discrete values) at time step $k$, and $u_{1}^{\min }\left(x_{2}, k\right)$ and $u_{1}^{\max }\left(x_{2}, k\right)$ come from (9) and (10) expressed at time step $k$.

From Bellman principle, the minimum cost-to-go $V_{k}\left(x_{k}\right)$ for the time interval $[k, N], 0 \leq k \leq N-1$, is then expressed as follows

$$
V_{k}\left(x_{k}\right)=\min _{u_{k} \in U}\left(L\left(x_{k}, u_{k}, k\right) \Delta t+V_{k+1}\left(x_{k}+f\left(x_{k}, u_{k}, k\right) \Delta t\right)\right),
$$

where $f\left(x_{k}, u_{k}, k\right)$ is the system dynamics given by:

$$
x_{k}+f\left(x_{k}, u_{k}, k\right)=x_{k+1}=\left\{\begin{array}{l}
x_{1, k+1}=x_{1, k}+f_{1}\left(u_{k}, k\right) \Delta t, \\
x_{2, k+1}=x_{2, k}+u_{3, k} .
\end{array}\right.
$$

At time $N$, the cost function is

$$
V_{N}\left(x_{N}\right)=g\left(x_{1, N}\right) .
$$

This optimization problem is solved backward from final time step to initial time step using a discretization of function $V$ in the control space and in the state space, that gives a 3-D grid (time $t$, state of charge $x_{1}$, and engine state $x_{2}$ nodes). A standard time step used in our examples is $\Delta t=0.5 \mathrm{~s}$, the discretization step $\Delta x_{1}$ for the state $x_{1}$ is $0.25 \%$, and $x_{2}$ takes only 0 or 1 values. Thus, the number of state nodes is $M=$ $2\left(\left(x_{1}^{\max }-x_{1}^{\min }\right) / \Delta x_{1}\right)$. A standard DP algorithm consists in determining, at each step $k$ and at each state value, the control feasible set $U\left(x_{k}, k\right)$, and calculating the optimal control that minimizes the sum $\left(L\left(x_{k}, u_{k}, k\right) \Delta t+V_{k+1}\left(x_{k}+f\left(x_{k}, u_{k}, k\right) \Delta t\right)\right)$.

Once initial time step is reached, a control law synthesis can be done, starting from initial conditions, minimizing again $L\left(x_{k}, u_{k}, k\right) \Delta t+V_{k+1}\left(x_{k}+f\left(x_{k}, u_{k}, k\right) \Delta t\right)$, and integrating state equations.

As the number of control is relatively small, about one hundred chosen controls, it's easy to select the optimal one by a simple minimization procedure.

This method allows a fast optimization: $(N-1) M$ constrained optimization problems (13) of only three parameters $u_{1, k}, u_{2, k}$ and $u_{3, k}$ are solved with a fine time discretization of the variables. This provides the optimal power repartition $u_{k}^{*}$ at each time step (we refer to Guilbaud (2002) for some theoretical results on the convergence of the method and error estimations).

A direct constrained optimization of (11) is an alternative method but leads to a large non linear optimization problem with a large number of inequality constraints. This is the reason why the DP algorithm is often preferred when the number of state variables is small (one or two state variables). 
Table 1 Fuel consumption for the reference case

\begin{tabular}{lll}
\hline & Fuel consumption $(1 / 100 \mathrm{~km})$ & Gain (\%) \\
\hline Conventional vehicle & 4.76 & \\
HEV & 3.76 & $20.99 \%$ \\
\hline
\end{tabular}

\section{Variations of the size of some powertrain elements}

On conventional vehicles, the maximal engine power is mainly defined by its displacement. Economic vehicles have a small engine, with a small fuel consumption, but with a low maximal torque. When engine displacement is higher, fuel consumption is higher, but maximal engine torque is also higher.

In hybrid vehicles, engine displacement has still almost the same impact on fuel consumption. However, the presence of a second energy source, which implies at least an electric motor and a battery, gives other degrees of freedom to decrease the fuel consumption.

In this study, the optimization of gear shifting is not presented, because gear shifting is imposed on the NEDC cycle. However, it is possible to impose a penalty at each time the gear is shifted.

The following results have been obtained by testing different sizes of elements of the powertrain. This approach has been preferred to parametric optimization, which is a quite complicated problem. The reader can nevertheless see some examples in Bonnans et al. (2002).

\subsection{Reference case}

The reference case is a Citroën C1 with a $1000 \mathrm{cc}$ gasoline engine. We consider on this vehicle that an electric motor of $10 \mathrm{~kW}$ is located downstream of the gearbox, at the same level as the wheels, and that a battery of $1.3 \mathrm{~kW} / \mathrm{h}$ provides the electric energy to the motor. The potential of this vehicle is assessed on the NEDC cycle, and gives the results summarized in Table 1.

\subsection{Variations of battery capacity with constant battery weight}

The battery dynamic (5) depends on the battery capacity: for a constant control, the battery dynamic is bigger as the battery capacity is smaller. As a result, the state of charge limits, $x_{1}^{\min }$ and $x_{1}^{\max }$, can be more often reached with a very small battery than with a big battery.

As the system dynamic does not depend on the state $x_{1}$, the fuel consumption will not evolve with the battery capacity as soon as the state of charge remains inside its bounds $x_{1}^{\min }, x_{1}^{\max }$ without touching them. Table 2 gives optimal fuel consumption on NEDC cycle for varying capacities.

\subsection{Variations of battery capacity and battery weight}

By considering the variations of battery capacity and the corresponding variations of its weight, not only the available electric power is changed, but also the global weight 
Table 2 Study of the impact of the battery capacity
Fuel consumption Gain (\%)

$(1 / 100 \mathrm{~km})$

\begin{tabular}{llll}
\hline Conventional vehicle & & 4.76 & \\
HEV with battery & $0.325 \mathrm{kWh}$ & 3.78 & $20.40 \%$ \\
& $0.65 \mathrm{kWh}$ & 3.76 & $20.99 \%$ \\
& $1.3 \mathrm{kWh}$ & 3.76 & $21 \%$ \\
& $2.6 \mathrm{kWh}$ & 3.76 & $21 \%$ \\
& $5.2 \mathrm{kWh}$ & 3.76 & $21 \%$ \\
\hline
\end{tabular}

the battery capacity with weight variations
Fuel consumption Gain (\%) $(1 / 100 \mathrm{~km})$

\begin{tabular}{llll}
\hline & & $\begin{array}{l}\text { Fuel consumption } \\
(1 / 100 \mathrm{~km})\end{array}$ & Gain (\%) \\
\hline Conventional vehicle & & 4.76 & \\
HEV with battery & $0.325 \mathrm{kWh}$ & 3.78 & $20.40 \%$ \\
& $0.65 \mathrm{kWh}$ & 3.76 & $20.84 \%$ \\
& $1.04 \mathrm{kWh}$ & 3.76 & $21.01 \%$ \\
& $1.3 \mathrm{kWh}$ & 3.76 & $20.99 \%$ \\
& $1.625 \mathrm{kWh}$ & 3.76 & $20.90 \%$ \\
& $1.95 \mathrm{kWh}$ & 3.76 & $20.79 \%$ \\
\hline
\end{tabular}

of the vehicle. In this context, the necessary power to match the requested vehicle speed of the cycle becomes higher as the weight of the battery increases. Thus, the variation of battery capacity causes the engine to change its operating points: same engine speeds, but different requested torques. Also, the vehicle will potentially be able to recover much more electric energy during braking, if control constraints are not activated. Consequently, the analysis of these results is not trivial.

We consider in the following that the battery weight varies according to $1 \mathrm{~kg}$ for $50 \mathrm{~W}$ h. The Table 3 shows obtained results.

It is noticeable that those results show a different trend than the results of Table 2. An optimal value is reached for $n_{\text {capa }}=1.04 \mathrm{~kW} \mathrm{~h}$, as seen on Fig. 2.

\subsection{Variations of maximal and minimal electric motor torques}

The car manufacturers are interested in estimating the best size of an electric motor for a hybrid vehicle, according to its use, as there is no need to have a very powerful motor if half of its maximum power is never reached.

The variations of maximal and minimal electric motor power may change the fuel consumption, but it also changes the state of charge trajectory (see results in Table 4).

For this vehicle used on the NEDC cycle, the fuel consumption does not evolve anymore if the electric motor power is larger than $P=15 \mathrm{~kW}$. Smaller powers of electric motor do not affect much the fuel consumption, as the gain for an electric motor is still $20.15 \%$ for a power of $5 \mathrm{~kW}$. 


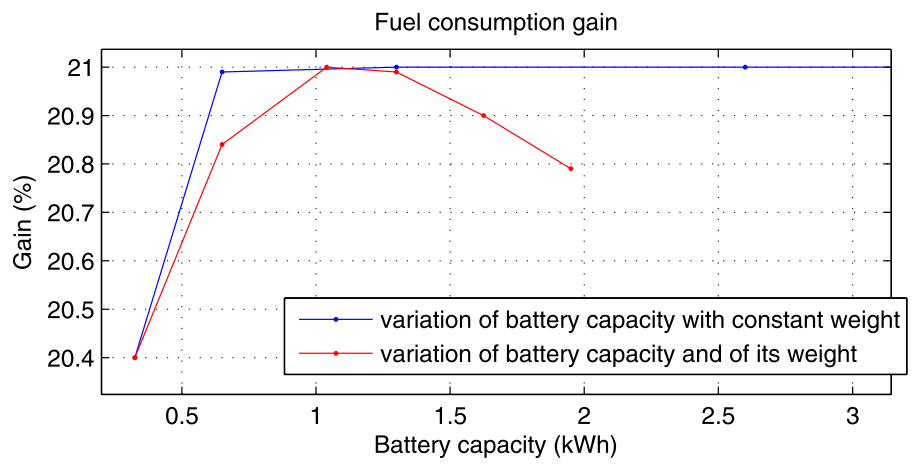

Fig. 2 Variation of gain of fuel consumption with battery capacity

Table 4 Study of the impact of the maximal motor power
Fuel consumption

$(1 / 100 \mathrm{~km})$

\subsection{6}

Conventional vehicle

3.80

3.76

HEV with motor $P=10 \mathrm{~kW}$

3.74

HEV with motor $P=20 \mathrm{~kW}$
$20.15 \%$

Gain $(\%)$

$20.99 \%$

$21.25 \%$

$21.25 \%$

\section{Real-time control strategy}

\subsection{Validation of DP results on a more realistic model}

Results obtained with the dynamic programming applied on the Matlab model are tested on a more realistic model implemented in AMESim, corresponding to the reference case, see Fig. 3. By comparison with the Matlab model used for optimization, this AMESim model includes all axle inertias, lag times of engine and electric motor, and a driver model which controls acceleration and brake pedal to follow the speed request from the cycle. Figure 4 shows the behavior of AMESim model with the optimal control of electric motor obtained from dynamic programming on the Matlab model.

Figure 4(a) shows the effective vehicle speed (blue), compared with the speed request from the cycle (red). Figure 4(b) and (d) show the motor and engine torques, while Fig. 4(e) specifies if the engine is started or stopped. Figure 4(c) shows a comparison between optimal SOC trajectory obtained with Matlab model, and the one obtained with AMESim model.

The global fuel consumption obtained with AMESim model is $310.2 \mathrm{~g}$ $(3.81 \mathrm{l} / 100 \mathrm{~km})$ while the one with Matlab model is $310.34 \mathrm{~g}(3.75 \mathrm{l} / 100 \mathrm{~km})$, but the vehicle linear displacement is not the same: Matlab model covers $11.01 \mathrm{~km}$, but AMESim model only covers $10.84 \mathrm{~km}$, because of inertia that cause a bad follow-up of the vehicle cycle at low speeds. The resulting error between the two models is about $1.5 \%$. 


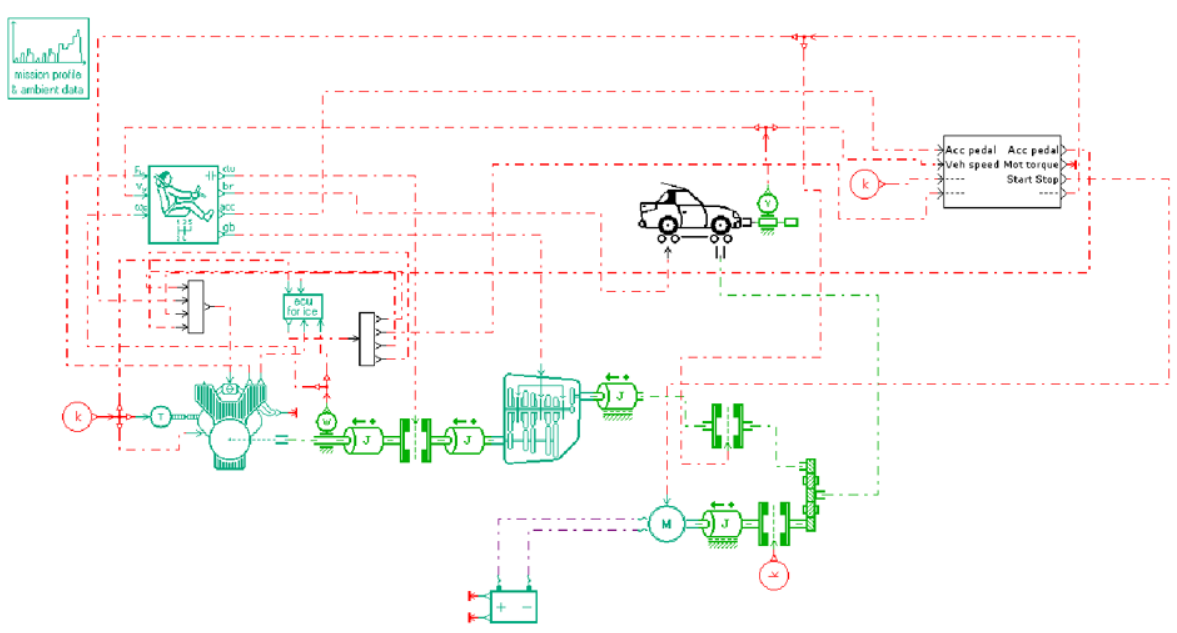

Fig. 3 Validation AMESim model

\subsection{Real-time control strategy}

In this section, suboptimal control law is derived from the optimization results. The chosen real-time control law is the Equivalent Consumption Minimization Strategy (Sciarretta et al. 2004; Guzzella and Sciarretta 2005; Paganelli et al. 2002): it is based on instantaneous equivalent fuel consumption, the battery being considered as a second energy source. ECMS aims to choose the cheapest energy source, between fuel tank and battery storage.

This strategy is inspired by the Pontryagin's Principle, which set optimality conditions for the unconstrained continuous optimization problem (4). Some important theoretical results can be found in Pontryagin et al. (1965). To apply this strategy, we form the Hamiltonian function $\mathcal{H}$, associated to the problem (4) without considering the state constraints, and given by

$$
\mathcal{H}(x(t), u(t), p(t), t)=\hat{L}(x(t), u(t), t)+p(t) \dot{x}_{1}(t),
$$

where $\hat{L}(x(t), u(t), t) \Delta t$ represents the variation of fuel consumption, and given by

$$
\hat{L}(x(t), u(t), t)= \begin{cases}L_{1}(u(t), t) & \text { if } x_{2} \neq 0 \\ 0 & \text { if } x_{2}=0\end{cases}
$$

$\dot{x}_{1}$ corresponds to the variation of state of charge over a time step, and $p$ is a Lagrange multiplier associated with the constraint $\dot{x}_{1}(t)=f_{1}(u(t), t)$. In this strategy, the optimal control is the admissible one which minimizes $\mathcal{H}$, taking into account all the control constraints. The same models as the ones used in dynamic programming algorithm are used in ECMS, which is the advantage of this model-based strategy. 

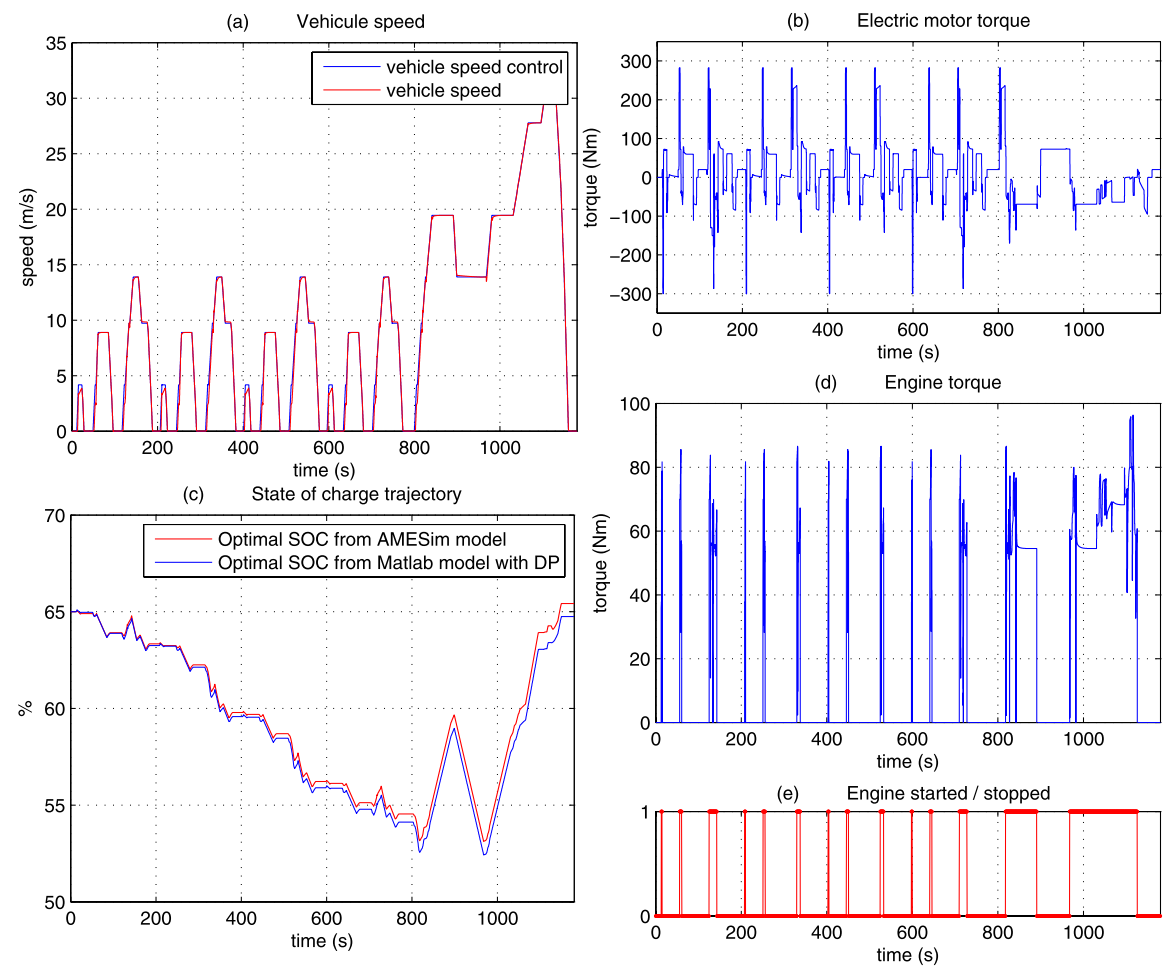

Fig. 4 Results of optimal control applied on AMESim model

\subsection{Meaning of $p$}

The coefficient $p$ corresponds to the price of electric energy. The larger is $p$, the more expensive is the electrical energy, and the more interesting to be recovered. The smaller is $p$, the cheaper is the electrical energy, and the more interesting to be used to power the vehicle conjointly with the engine.

The variation of $p$ depends on the time evolution of the dynamic state variable $x_{1}$, according to the Euler-Lagrange equations, namely

$$
\dot{p}(t)=-\frac{\partial \mathcal{H}}{\partial x_{1}}\left(x(t), u^{*}(t), p(t), t\right) .
$$

As either $\hat{L}$ or $\dot{x}_{1}$ do not depend on $x_{1},(18)$ gives

$$
\dot{p}(t)=0 .
$$

As a results, when no state constraint is active, $p$ is constant for the considered system (6). When a state constraint becomes active, the sign of $\dot{p}$ is completely known, depending on the active constraint: $x=x^{\min }$ or $x=x^{\max }$. Indeed, if the augmented 
Hamiltonian is written, with state constraints, we get

$$
\begin{aligned}
\mathcal{H}(x(t), u(t), p(t), t)= & \hat{L}(x(t), u(t), t)+p(t) \dot{x}_{1}(t)+\lambda_{1}(t)\left(x_{1}^{\min }-x_{1}(t)\right) \\
& +\lambda_{2}(t)\left(x_{1}(t)-x_{1}^{\max }\right),
\end{aligned}
$$

where $\lambda_{1} \geq 0$ and $\lambda_{2} \geq 0$ are Lagrange multipliers associated with state constraints $x_{1}^{\min }-x_{1} \leq 0$ and $x_{1}-x_{1}^{\max } \leq 0$. Solving $\dot{p}=-\frac{\partial H}{\partial x_{1}}$ leads to $\dot{p}=\lambda_{2}-\lambda_{1}$. One can verify that if $x_{1}=x_{1}^{\mathrm{min}}$, then $\lambda_{2}=0$ and $\lambda_{1} \geq 0$ meaning that $\dot{p} \geq 0$. The same idea is used with the second state constraint.

\subsection{Control of $p$}

In ECMS, the value of $p$ is often controlled thanks to rules of Delprat et al. (2004), Liu and Peng (2006), mainly depending of the state of charge. Indeed, as the future is not known, it can be better to keep the state of charge $x_{1}$ far from its bounds, and to control $p$ as a function of $x_{1}$ with a feedback controller. However, in this paper, we consider that $p$ remains constant, and we just try to show the potential of this strategy with an adequate initial value of $p$.

An estimation of $p$ can be obtained by calculating the equivalent Lagrange multiplier with the dynamic programming results. From Bryson and Ho (1975), equivalence between Pontryagin's principle and dynamic programming in continuous time can be found, assuming that $V$ is differentiable, with

$$
p(t)=\frac{\partial V}{\partial x_{1}}\left(t, x_{1}\right)
$$

where $V\left(t, x_{1}\right)$ corresponds to the cost-to-go function.

To estimate the value of $p$, we calculate the partial derivative of $V$ (defined in (13)) with respect to $x_{1}$ with finite differences, for each step $k$. Using theses results allows to estimate that the average value ${ }^{1}$ of $p$ should be into the range $[-3400 ;-3000]$. Because of some differences between the model used with dynamic programming and the AMESim model, a trial \& error method has been applied to end up with $p=-3075 .^{2}$ This value allows to reach a final state $x_{1}(T)$ close to the initial state $x_{1}(0)$.

\subsection{Results of the ECMS Real-time controller}

The Fig. 5 shows some results obtained with this real-time control strategy, with a correct value of $p$.

Figure 5(a) shows that the hybrid vehicle still follows the speed request from the cycle. However, some differences appear on the state of charge, Fig. 5(b). The fuel

\footnotetext{
${ }^{1}$ In practice, a shooting algorithm can be used by setting the initial value of $p$, integrating the system equations, and iterating on the initial value of $p$ to reach the desired final state of charge.

${ }^{2}$ If the variations of fuel and chemical energies are used instead of the variations $\hat{L}(u(t), t) \Delta t$ and $\dot{x}_{1}(t) \Delta t$, the coefficient $p$ can be scaled to a smaller value.
} 

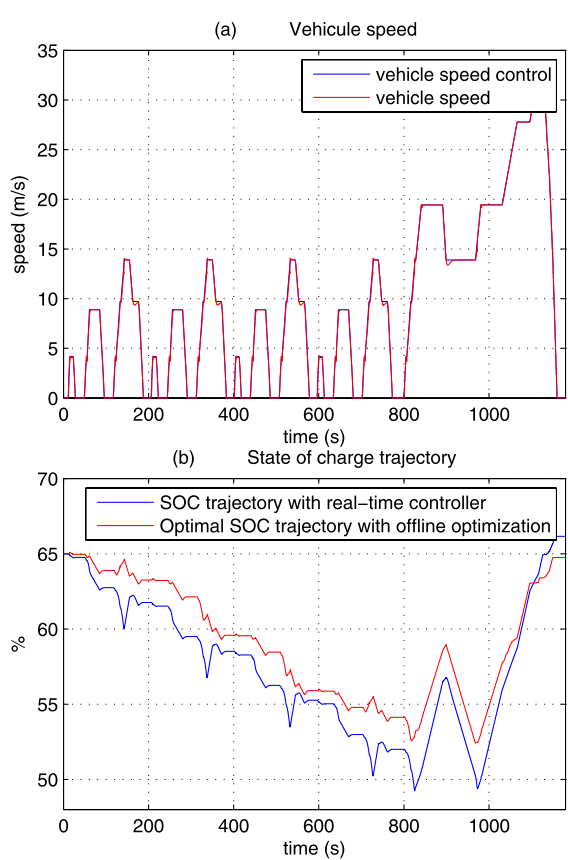

(c) Electric motor torque

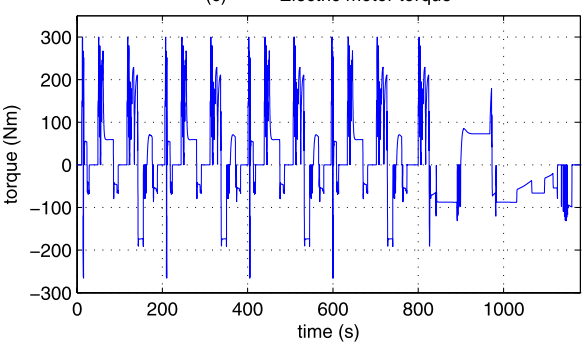

(d) Engine torque

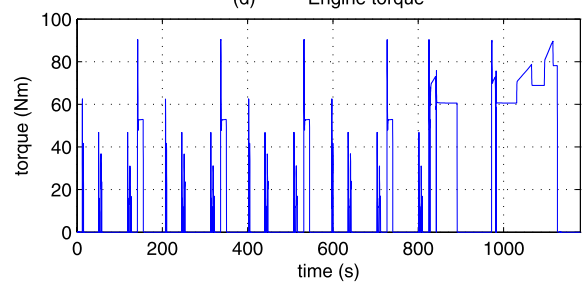

(e) engine started/stopped

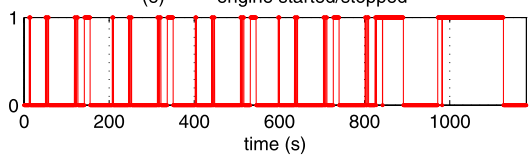

Fig. 5 Results obtained with a sub-optimal strategy applied on AMESim model

consumption obtained with this sub-optimal strategy is $326.8 \mathrm{~g}$, corresponding to $3.97 \mathrm{l} / 100 \mathrm{~km}$. Compared to conventional vehicle, this controller-with an ideal value of $p$ in this example-allows to save $16.6 \%$ of fuel on the NEDC cycle. Some rules to control $p$ with the state of charge should be implemented to make this controller more robust.

\section{Conclusion}

In this paper, has been presented a study of a full hybrid vehicle, with a classical offline optimization tool, and an example of a real-time control strategy inspired from optimal control theory.

A simple model in Matlab has been implemented and coupled with a dynamic programming algorithm. Through this model, an engine startup cost $L_{2}$ has been introduced in the optimal control problem, thanks to a discrete variable $x_{2}$, to take into account the extra fuel consumption of the engine in order to reach its idle speed. This penalization term in the cost function avoids too many successive engine stops and engine starts, and is usually never considered in this kind of optimal control problems.

This optimization tool allows to estimate the optimal sizes and powers of the elements of hybrid powertrain. Nevertheless, these results, obtained on the NEDC cycle, depend on the chosen driving cycle: so the optimal sizes can be a little different on other cycles. 
After a validation of the optimal trajectory and torques applied on a more realistic model in AMESim, a model-based sub-optimal controller has been implemented, inspired by Pontryagin's Principle and optimality conditions. In the paper, we briefly show how to take into account some dynamic programming results to initialize the value of $p$.

However, even if an average value of $p$ can be estimated from offline optimization results, which provides an initial value, the choice of an adequate initial value remains a delicate task, and $p$ should be tuned regarding to the evolution of the state of charge of the battery, and to the type of the cycle.

\section{References}

Anatone M, Cipollone R, Donati A, Sciarretta A (2005) Control-oriented modeling and fuel optimal control of a series hybrid bus. SAE Technical Paper

Assanis D, Delagrammatikas G, Fellini R, Filipi Z, Liedtke J, Michelena N, Papalambros P, Reyes D, Rosenbaum D, Sales A, Sasena M (1999) Optimization approach to hybrid electric propulsion system design. Mech Based Des Struct Mach Int J 27(4):393-421

Beck R, Bollig A, Abel D (2007) Comparison of two real-time predictive strategies for the optimal energy management of a hybrid electric vehicle. Oil Gas Sci Technol—Rev IFP 62(4):635-643

Bonnans JF, Guilbaud T, Ketfi-Cherif A, Sagastizábal C, von Wissel D, Zidani H (2002) Parametric optimization of hybrid car engines. Optim Eng 334-335:73-84

Bryson E, Ho YC (1975) Applied optimal control. Hemisphere, Washington

Delprat S et al (2004) Control of a parallel hybrid powertrain: optimal control. IEEE Trans Veh Technol 53(3):872-881

German JM (2003) Hybrid powered vehicles. Society of Automotive Engineers International, ISBN 0-7680-1310-0.

Guilbaud T (2002) Méthodes numériques pour la commande optimale. Thesis, Université de Paris, VI

Guzzella L, Sciarretta A (2005) Vehicle propulsion systems. Springer, Berlin

Liu J, Peng H (2006) Control optimization for a power-split hybrid vehicle. In: Proceedings of the 2006 American control conference, Minneapolis, USA, June, pp 461-471

Paganelli G, Delprat S, Guerra TM, Rimaux J, Santin JJ (2002) Equivalent consumption minimization strategy. In: IEEE 55th vehicular technology conference (VTC Spring 2002), vol 4, pp 2076-2081

Pontryagin LS, Boltyanskii VG, Gamkrelidze RV, Mishchenko EF (1965) The mathematical theory of optimal processes. CRC Press, Boca Raton

Sciarretta A, Guzzella L, Back M (2004) A real-time optimal control strategy for parallel hybrid vehicles with on-board estimation of the control parameters. In: Proceedings of IFAC symposium on advances in automotive control AAC04, pp 502-507

Scordia J (2005) Systematic elaboration of online energy management laws for hybrid vehicles. In: Proceedings of the EVS 21-electric vehicle symposium, Monte Carlo, Monaco

Sharer P, Rousseau A, Nelson P, Pagerit S (2006) Vehicle simulation results for plug-in HEV battery requirements. In: EVS22

Sundström O, Guzzella L, Soltic P (2008) Optimal hybridization in two parallel hybrid electric vehicles using dynamic programming. In: Proceedings of the 17th world congress of the international federation of automatic control, Seoul, Korea, July 6-11, 2008, pp 4642-4647

Tate ED, Boyd SP (2007) Finding ultimate limits of performance for hybrid electric vehicles. SAE Trans 109(6):2437-2448

Wu B, Lin C-C, Filipi Z, Peng H, Assanis D (2002) Optimization of power management strategies for a hydraulic hybrid medium truck. In: Proceedings of the 6th international symposium on advanced vehicle control (AVEC '02), Hiroshima, Japan, 2002, pp 559-564 